\title{
Estudo da manifestação incomum da actinomicose em região periapical
}

\author{
Study of the unusual manifestation of actinomycosis in the periapical region
}

\author{
Eugênio Braz Rodrigues Arantes ${ }^{1}$ \\ TAIANE DOS SANTOS LOPES ${ }^{2}$ \\ Bárbara Barreto Pacheco Valentim² \\ Vitor Figueiredo FerRer de Almeida ${ }^{3}$ \\ Rodrigo Figueiredo de Brito Resende ${ }^{4}$
}

\begin{abstract}
RESUMO
Objetivo: Realizar uma revisão da literatura descrevendo as características clínicas, radiográficas e as formas de tratamento das manifestações periapicais da infecção por actinomicose. Métodos: Foram selecionados artigos em português, inglês e espanhol, de 1977 até a presente data, nos bancos de dados dos Periódicos CAPES, PubMed/MEDLINE, ScienceDirect, SciELO e BVS. Resultados: Foram obtidos 25 artigos no total, sendo selecionados 13 após critérios de inclusão e exclusão. As variantes avaliadas foram clínicas, radiográficas, histórico de trauma e forma de tratamento utilizada. Conclusão: A manifestação periapical da actinomicose tem sido frequentemente identificada e o uso dos exames de imagem, culturas bacterianas e biópsias cirúrgicas se tornam de vital importância para a realização de um adequado diagnóstico das colônias de actinomicetos.
\end{abstract}

Palavras-chave: Actinomicose; Doenças Periapicais; Abscesso Periapical.

\begin{abstract}
Objective: Conduct a review of the literature describing the clinical, radiographic and forms of treatment of periapical actinomycosis manifestations of infection. Métodos: Articles in portuguese, english and spanish were selected from 1977 to the present day in the databases of CAPES, PubMed/MEDLINE, ScienceDirect, SciELO and BVS journals. Results: A total of 25 articles were obtained and being selected 13 after inclusion and exclusion criteria. The variants evaluated were clinical, radiographic, history of trauma and form of treatment used. Conclusion: The periapical manifestation of actinomycosis has often been identified and the use of imaging exams, bacterial cultures and surgical biopsies are of vital importance for the adequate diagnosis of actinomyces colonies.
\end{abstract}

Key-words: Actinomycosis; Periapical Diseases; Periapical Abscess.

\footnotetext{
Cirurgião(ã)-dentista, Especialista em Estomatologia pela Universidade Federal do Rio de Janeiro e Residente do Serviço de Cirurgia e Traumatologia Bucomaxilofacial da Universidade Federal Fluminense/Hospital Federal dos Servidores do Estado, Rio de Janeiro/ RJ, Brasil.

2 Cirurgiã-dentista, Especialista em Estomatologia pela Universidade Federal do Rio de Janeiro, Rio de Janeiro/RJ, Brasil. Acadêmico de Odontologia, Faculdade de Odontologia da Universidade Federal Fluminense, Niterói, Rio de Janeiro/RJ, Brasil.

4 Especialista em Cirurgia e Traumatologia Bucomaxilofacial pela Universidade Gama Filho/Hospital de Força Aérea do Galeão, Rio de Janeiro/RJ, Brasil. Mestre e Doutor em Odontologia pela Universidade Federal Fluminense, Niterói/RJ, Brasil
} 


\section{INTRODUÇÃO}

O Actinomyces israelli é o agente etiológico da infecção crônica e supurativa conhecida como actinomicose. A infecção pode se apresentar em diferentes localizações: abdominopélvica, pulmonar e cervicofacial, sendo esta última a forma mais comum, onde a região submandibular é a mais acometida. ${ }^{1}$ Os fatores de risco à infecção cervicofacial incluem: exodontia prévia, cárie dentária, doença periodontal, infecções secundárias e dano tecidual local. ${ }^{2}$

As bactérias pertencentes ao grupo Actinomyces são componentes da microbiota oral normal que, quando em desequilíbrio, podem torna-se patogênica. ${ }^{1} \mathrm{O}$ fator mais comum associado a esse desequilíbrio é a falta de cicatrização desencadeada por micro-organismos que desenvolvem lesões inflamatórias como infecção persistente ou secundária. Esses micro-organismos podem acometer mais raramente a região periapical, sendo uma grande causa de falhas do tratamento endodôntico. ${ }^{3}$ A actinomicose periapical é uma infecção extrarradicular, independente da infecção no interior do canal, que invade os tecidos perirradiculares inflamados. Quando a lesão acomete os ossos gnáticos, pode gerar um aspecto radiográfico similar a um granuloma ou lesão cística periapical. ${ }^{4}$

As características clínicas dessa infecção se caracterizam por apresentar um crescimento lento, a idade dos pacientes acometidos varia de 16 a 75 anos (média de 42 anos), com predominância em pacientes do sexo masculino e com prevalência variada entre a maxila e mandíbula. ${ }^{5}$ A lesão pode progredir do osso envolvido para os tecidos moles como os seios da face e se exteriorizar para a cavidade oral ou no tecido cutâneo. O diagnóstico é desafiador devido à não especificidade das suas características clínicas. ${ }^{6}$ Radiograficamente, apresentam-se como lesões radiolúcidas, ovoides, únicas e com margens bem definidas acometendo, mais comumente, a região de molares e pré-molares (Figura 1). ${ }^{6,7,8}$

Devido ao aspecto radiográfico ser muito semelhante ao de um cisto inflamatório periapical, a conduta deve ser ancorada no tratamento ou retratamento endodôntico, seguido de biópsia excisional e após confirmação da histopatologia realizar prescrição medicamentosa com antibiótico, sendo a penicilina de primeira escolha. $O$ resultado histopatológico é eficiente para este diagnóstico, resolução final e a necessidade da terapia antibiótica. ${ }^{8}$

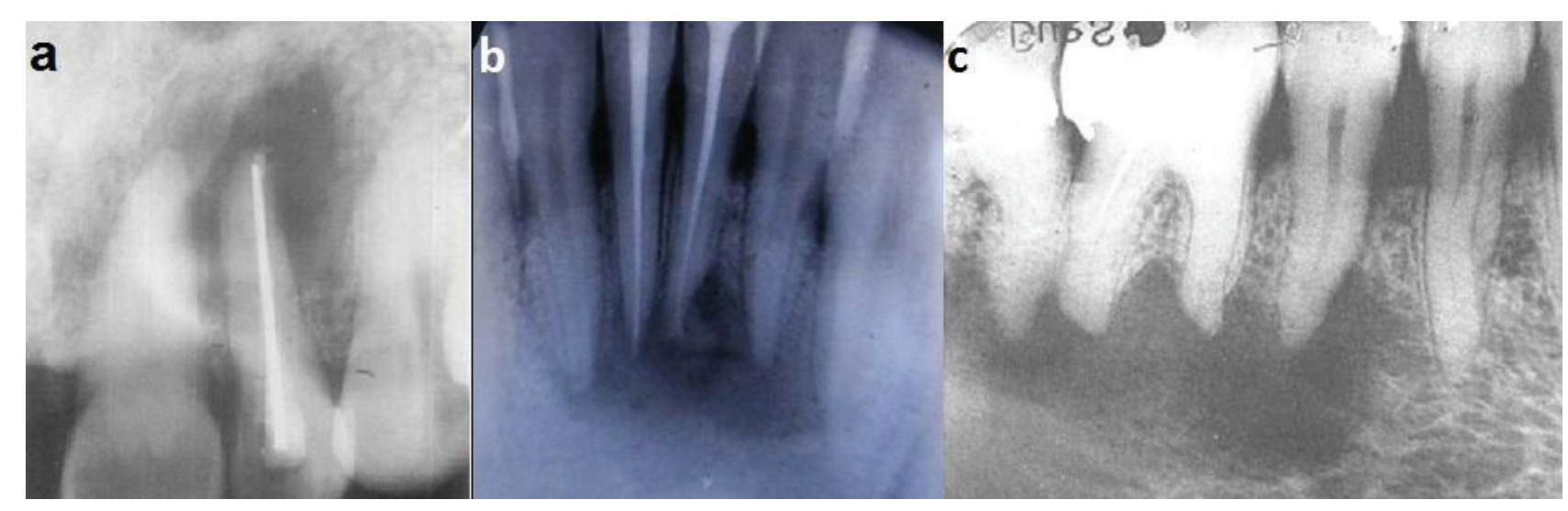

Figura 1: A) Imagem radiolúcida, bem definida e bem delimitada associada ao ápice de elemento dentário com tratamento endodôntico prévio; B) Imagem radiolúcida, irregular de limites indefinidos e difusos; C) Imagem radiolúcida extensa, difusa e bem delimitada.

Fontes: A- Freeman, Zimmermann, Ferrillo. Oral Surg 1981; B- Pasupathy et al., BMJ Case Rep 2012; C- Sakellariou. Endod Dent Traumatol 1996. 
O propósito deste trabalho é revisar os trabalhos da literatura contendo as características clínicas e radiográficas mais comuns da actinomicose associada à região periapical dos elementos dentários e as principais formas de tratamento utilizadas.

\section{Material e Métodos}

Foi realizada uma revisão da literatura com o objetivo de avaliar características clínicas, radiográficas e as formas de tratamento de relatos de casos clínicos presentes na literatura e que apresentassem a lesão inflamatória periapical por uma infecção por actinomicose. Em relação ao levantamento bibliográfico, foram realizadas consultas nas bases de dados dos Periódicos CAPES, Literature Analysis (PubMed/ MEDLINE), ScienceDirect, Scientific Electronic Library Online (SciELO) e BVS com os seguintes critérios de inclusão: relatos de casos publicados nos idiomas português, espanhol e inglês, que tenham como ênfase as características clínicas, radiográficas, as formas de tratamento e a presença ou não de histórico de trauma, publicados de 1977 até 2018 e com resumo disponível. Os critérios de exclusão utilizados no estudo foram: pesquisas realizadas em animais, artigos em outra língua que não o espanhol, inglês ou português e revisões da literatura. Os termos utilizados para a busca segundo os descritores em Ciência da Saúde (DeCs) e Medical Subject Headings (MeSH) foram: infecções por actinomycetales (actinomycetales infections), actinomicose (actinomycosis), abscesso periapical (periapical abscess) e granuloma periapical (periapical granuloma).

O fluxograma da figura 2 apresenta o caminho de decisão para a seleção final dos artigos.

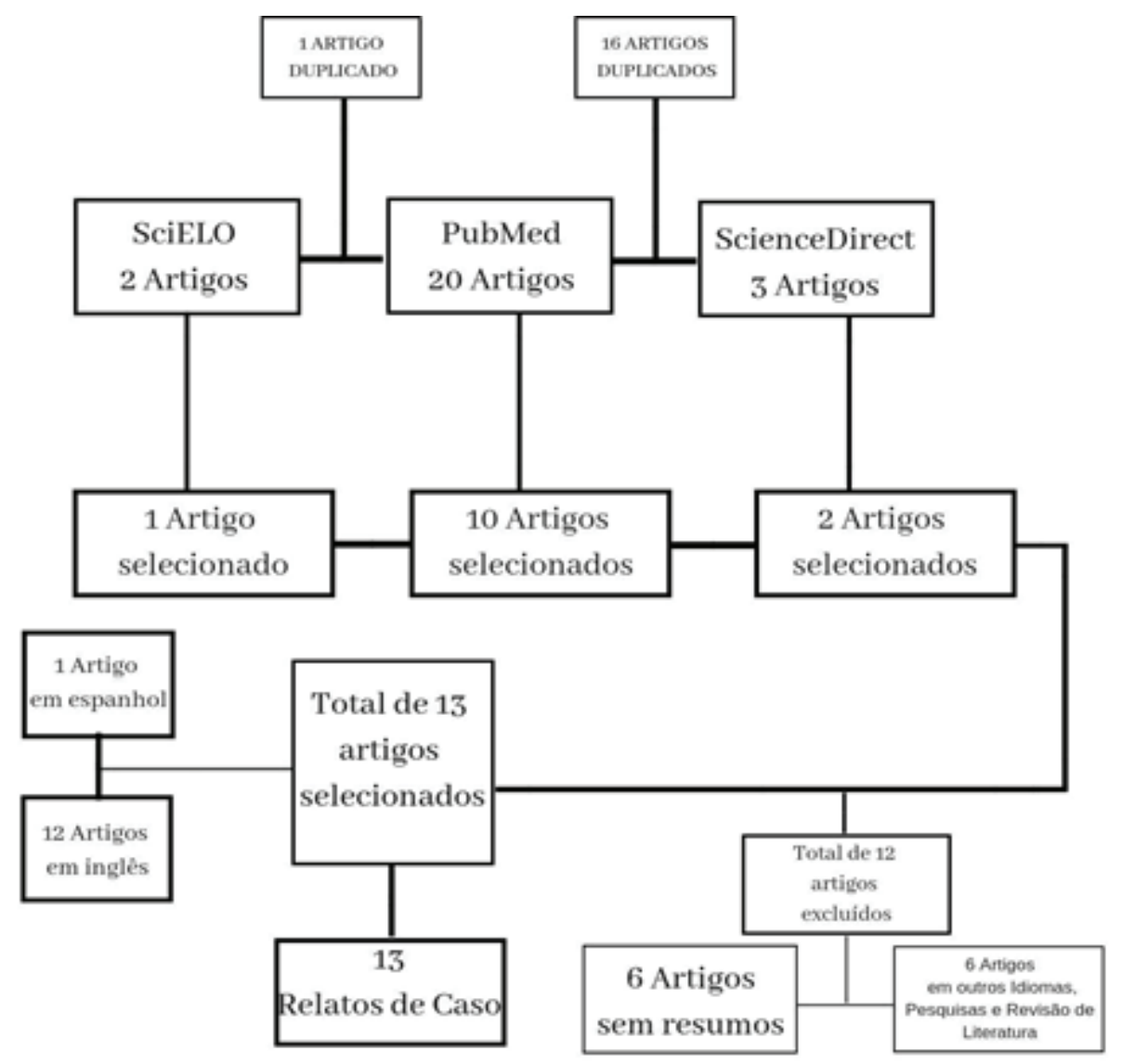

Figura 2: Fluxograma dos aRtigos CIENTíficos. 


\section{Resultados}

Foram encontrados 25 artigos, e considerando os critérios de inclusão, exclusão e as variantes necessárias, foram incluídos para análise apenas 13 artigos. Na tabela 1 estão apresentados os artigos e respectivos autores localizados através dos descritores utilizados nas bases de dados e com período de publicação dos artigos, como estabelecido nos critérios de inclusão. A maior parte foi publicada em inglês (12 artigos), ainda que tenham sido estabelecidos como critério para a busca, artigos publicados em português, espanhol e inglês.

Tabela 1: Dados clínicos, radiográficos e tratamento utilizado em casos de actinomicose periapical.

\begin{tabular}{|c|c|c|c|c|c|c|c|c|}
\hline $\mathbf{N}^{0}$ & Autor/ano & $\begin{array}{l}\text { Idade } \\
\text { Sexo }\end{array}$ & Trauma & Dentes & $\begin{array}{l}\text { Exame de } \\
\text { imagem }\end{array}$ & Sinais e sintomas & $\begin{array}{l}\text { Endodontia } \\
\text { Prévia }\end{array}$ & Tratamento Final \\
\hline 1 & $\begin{array}{l}\text { WESLEY et al } \\
\qquad 1977\end{array}$ & $15 / F$ & $\begin{array}{l}4 \text { anos } \\
\text { antes }\end{array}$ & $31 / 41$ & $\begin{array}{l}\text { Radiolúcida } \\
\text { bem } \\
\text { definida }\end{array}$ & $\begin{array}{c}\text { Drenagem } \\
\text { espontânea, fístula } \\
\text { intraoral e mobilidade } \\
\text { dentária. }\end{array}$ & Sim & $\begin{array}{l}\text { Exodontia, curetagem } \\
\text { apical e antibioticoterapia. }\end{array}$ \\
\hline 2 & $\begin{array}{l}\text { WEIR et al } \\
1982\end{array}$ & 18/F & $\begin{array}{l}10 \text { anos } \\
\text { antes }\end{array}$ & $11 / 12$ & Radiolúcida & $\begin{array}{c}\text { Fístula intraoral, } \\
\text { dentes positivos à } \\
\text { percussão e negativos } \\
\text { ao teste de vitalidade. }\end{array}$ & Sim & $\begin{array}{l}\text { Profilaxia antibiótica e } \\
\text { curetagem apical. }\end{array}$ \\
\hline 3 & $\begin{array}{c}\text { SAKELLARIU et al } \\
1996\end{array}$ & $56 / \mathrm{M}$ & $S / R$ & $\begin{array}{c}45 / 46 \\
47\end{array}$ & Radiolúcida & Aumento de volume. & Não & $\begin{array}{c}\text { Profilaxia antibiótica, } \\
\text { cirurgia periapical e } \\
\text { antibioticoterapia. }\end{array}$ \\
\hline 4 & $\begin{array}{l}\text { PASUPATHY et al } \\
2012\end{array}$ & 30/M & $S / R$ & $31 / 41$ & $\begin{array}{l}\text { Radiolúcida } \\
\text { irregular e } \\
\text { difusa }\end{array}$ & $\begin{array}{l}\text { Dor, drenagem } \\
\text { espontânea e fístula } \\
\text { intraoral. }\end{array}$ & Sim & $\begin{array}{l}\text { Profilaxia antibiótica, } \\
\text { curetagem apical e } \\
\text { apicectomia. }\end{array}$ \\
\hline 5 & ANGAJl et al 2011 & $63 / F$ & $S / R$ & 44 & Radiolúcida & Dor moderada. & Sim & $\begin{array}{l}\text { Extração dentária e } \\
\text { antibioticoterapia. }\end{array}$ \\
\hline 6 & $\begin{array}{c}\text { FREEMAN et al } \\
1981\end{array}$ & $S / R$ & $\begin{array}{l}33 \text { anos } \\
\text { antes }\end{array}$ & 22 & Radiolúcida & $\begin{array}{c}\text { Fístula intraoral e } \\
\text { dente desvitalizado. }\end{array}$ & Sim & $\begin{array}{c}\text { Cirurgia exploratória e } \\
\text { antibioticoterapia. }\end{array}$ \\
\hline 7 & $\begin{array}{l}\text { JAMSHIDI et al } \\
2015\end{array}$ & $40 / F$ & $S / R$ & 16 & Radiolúcida & $\begin{array}{c}\text { Fístula cutânea e } \\
\text { drenagem espontânea. }\end{array}$ & Sim & $\begin{array}{c}\text { Curetagem apical, } \\
\text { osteotomia e apicectomia. }\end{array}$ \\
\hline 8 & $\begin{array}{l}\text { SCOTTI et al } \\
2006\end{array}$ & $75 / F$ & $S / R$ & 33 & $\begin{array}{l}\text { Radiolúcida } \\
\text { bem } \\
\text { definida }\end{array}$ & Destruição coronária. & $S / R$ & $\begin{array}{l}\text { Extração dentária e } \\
\text { antibioticoterapia. }\end{array}$ \\
\hline 9 & $\begin{array}{l}\text { RICUCCl et al } \\
2008\end{array}$ & $32 / F$ & $S / R$ & 12 & Radiolúcida & $\begin{array}{c}\text { Fístula } \\
\text { intraoral, dor e } \\
\text { mobilidade dentária. }\end{array}$ & Sim & $\begin{array}{l}\text { Curetagem apical e } \\
\text { apicectomia. }\end{array}$ \\
\hline 10 & $\begin{array}{c}\text { FIGURES et al } \\
1991\end{array}$ & $37 / F$ & $S / R$ & 22 & Radiolúcida & $\begin{array}{l}\text { Aumento de volume } \\
\text { e dor. }\end{array}$ & Sim & Cirurgia periapical. \\
\hline 11 & $\begin{array}{c}\text { ASGARY and } \\
\text { ROGHANIZADEH } \\
2018\end{array}$ & $22 / F$ & $S / R$ & 36 & $\begin{array}{l}\text { Radiolúcida } \\
\text { bem } \\
\text { definida }\end{array}$ & $\begin{array}{l}\text { Dor moderada e } \\
\text { dentes sensiveis à } \\
\text { percussão. }\end{array}$ & $\operatorname{Sim}$ & $\begin{array}{l}\text { Terapia endodôntica, } \\
\text { apicectomia e } \\
\text { antibioticoterapia. }\end{array}$ \\
\hline 12 & $\begin{array}{l}\text { AL-HEZAIMI } \\
2010\end{array}$ & $24 / F$ & $S / R$ & $36 / 37$ & $\begin{array}{l}\text { Radiolúcida } \\
\text { bem } \\
\text { definida }\end{array}$ & $\begin{array}{l}\text { Dor moderada e fístula } \\
\text { cutânea. }\end{array}$ & Sim & $\begin{array}{l}\text { Terapia endodôntica, } \\
\text { curetagem apical, } \\
\text { apicectomia e } \\
\text { antibioticoterapia. }\end{array}$ \\
\hline 13 & $\begin{array}{l}\text { JEANSONNE } \\
2005\end{array}$ & $56 / F$ & $S / R$ & 25 & $\begin{array}{l}\text { Radiolúcida } \\
\text { irregular }\end{array}$ & $\begin{array}{l}\text { Aumento de volume } \\
\text { e dor. }\end{array}$ & Sim & $\begin{array}{l}\text { Terapia endodôntica, } \\
\text { curetagem apical, } \\
\text { apicectomia e } \\
\text { antibioticoterapia. }\end{array}$ \\
\hline
\end{tabular}

Legenda da tabela 1: F- feminino; M- masculino; $N^{\circ}$, número do caso; S/R, Sem relato. 
Ainda na tabela 1, foram expostos os casos em diferentes faixas etárias, de 15 a 75 anos de idade, obtendo a média de 40,6 anos, com uma predileção pelo sexo feminino 7:2. Não foi apresentada diferença entre os ossos maxilares, mas com um predomínio de $75 \%$ em região anterior, o que poderia ser associado à área de maior acometimento traumático, porém, apenas três casos relataram histórico de trauma antecedendo o surgimento da lesão.

A maioria relatou lesão com aspecto radiolúcido bem definido e circunscrito, apenas dois trabalhos descreveram a radiolucidez como irregular e difusa (Figura 1). Em $80 \%$ dos casos havia sido feito tratamento endodôntico previamente, apenas $10 \%$ não realizaram endodontia e um caso não foi relatado. Os sinais e sintomas tiveram diferentes apresentações, mas todos com características de infecção e os tratamentos escolhidos também tiveram abordagens distintas, variando os protocolos de acordo com seus autores.

\section{Dıscussão}

Dentre as manifestações da doença actinomicose na região cervico-facial a apresentação periapical, apesar de rara, representa uma infecção crônica de lento crescimento, e que se caracteriza pela colonização de cepas de actinomicetos na superfície dos canais radiculares, mais precisamente na região periapical. As principais causas para o desenvolvimento da actinomicose periapical são lesões cariosas, abscesso periapical e trauma dentário, que propiciam a instalação desses microorganismos. Por se tratar de uma infecção, a maneira como essa doença se manifesta clinicamente, a sua severidade e prognóstico serão variáveis entre os indivíduos e podem ser influenciadas por fatores como a via da infecção, ou seja, a sua causa e também pela presença ou ausência de um sistema imune competente. ${ }^{7,9,10}$

Clinicamente, os sinais e sintomas da actinomicose periapical são semelhantes aos do abscesso periapical comum. Dentre os sintomas mais comuns encontram-se a inflamação periapical persistente, fistulação recidivante, fibrose tecidual e lesões supurativas. ${ }^{8,} 10 \mathrm{~A}$ mobilidade do dente envolvido, descrita por Wesley ${ }^{11}$ e Ricucci' ${ }^{12}$, pode ser explicada pela extensão do processo inflamatório no tecido perirradicular. Jamshidi ${ }^{4}$ relatou uma lesão cutânea supurativa decorrente da actinomicose periapical que se apresentou de maneira persistente por aproximadamente um ano. $\mathrm{O}$ que pôde ser confirmado por Farhad et al.,13 em um relato de caso de paciente com fístula cutânea, que relataram que mesmo após a terapia endodôntica com regressão da lesão intraóssea, a lesão extraoral pode persistir. Mora et al., ${ }^{14}$ observando essas características, identificaram que em relação aos estágios da doença ela pode se apresentar crônica ou aguda, neste último ocorrendo drenagem e exposição com fistulação através de espaços faciais em decorrência das inserções musculares.

No que diz respeito à sua apresentação radiográfica, as lesões periapicais comuns apresentam aspectos indistinguíveis da lesão causada pela actinomicose periapical, que surge como uma imagem radiolúcida, bem definida e bem delimitada por um halo radiopaco, unilocular e usualmente oval associada à região periapical de um elemento dentário com alteração pulpar. ${ }^{6}$ Isso justifica a endodontia prévia descrita pela literatura, uma vez que a maioria das lesões inflamatórias da região apical responde positivamente e primariamente ao tratamento endodôntico. Porém, quando associado à actinomicose, a resposta não é sempre positiva devido à invasão independente das cepas de actinomicetos. ${ }^{5,13}$ 
Pasupathy et al. ${ }^{8}$ mostraram pela primeira vez uma apresentação radiográfica de aspecto irregular, sendo a única apresentação diferente das descritas pela literatura. Freeman et al. ${ }^{9}$ descreveram a mandíbula como área de predileção e de maior acometimento, porém, a igualdade entre os maxilares é defendida pela maioria dos autores, uma vez que as causas podem variar de quadrante e área afetada. Exceto, talvez, nos casos em que a causa inicial foi decorrente de trauma dentário, onde ocorre um predomínio de $70 \%$ na região anterior, o que poderia estar associado à região com maior índice de trauma. 5, 9, 14

O diagnóstico da actinomicose periapical é um desafio para o clínico devido à variação de suas manifestações clínicas e semelhança com outras lesões mais comuns. ${ }^{8,15}$ Quando realizada a cultura, método ideal para 0 diagnóstico, esta pode não ser obtida devido à proliferação exacerbada de outras bactérias decorrente do uso prévio de antibióticos. ${ }^{1}$ Neville et al. ${ }^{1}$ ainda propõem que a biópsia seja realizada como o exame mais importante para o diagnóstico, permitindo identificar colônias típicas de actinomicetos, e assim como o exame de cultura, o material para análise pode ser obtido no momento da cirurgia exploratória.

Os critérios para escolher qual opção terapêutica utilizar ainda são discutidos pela literatura, uma vez que, por ser tratar de uma infecção, a antibioticoterapia deve ser debatida e pode ser associada à curetagem cirúrgica apical ou ao tratamento endodôntico. ${ }^{1}$ Ainda que seja impossível definir um protocolo de tratamento único, Freeman et al. ${ }^{9}$ optaram por uma antibioticoterapia conservadora com duração de seis dias, questionando os 60 dias prescritos por Oppenheimer et al. ${ }^{10}$ Além dessa dificuldade para se estabelecer um método único, Mora et al. ${ }^{14}$ mostraram que os actinomicetos possuem sensibilidade alta à Penicilina, Ampicilina, Eritromicina,
Cefalosporinas e resistência à Gentamicina.

Neville et al. ${ }^{1}$ sugerem que somente a remoção cirúrgica do tecido periapical infectado pode induzir bons resultados e o tratamento da causa inflamatória radicular pode ser realizado normalmente após.

\section{Considerações finaIS}

A actinomicose periapical pode ser identificada em biópsias cirúrgicas de lesões inflamatórias periapicais, ressaltando a importância dos cirurgiões sempre encaminharem as peças cirúrgicas para avaliação histopatológica. A cirurgia associada ao uso de antibióticos em curto prazo se mostra eficaz no tratamento desta condição.

\section{ReferÊnCIAS}

1. Neville BW, Damm DD, Allen CM, Bouquot J. Oral and maxillofacial pathology. 3rd ed. Philadelphia: WB Saunders; 2008.

2. Volante M, Contucci AM, Fantoni M, Ricci R, Galli J. Cervicofacial actinomycosis: still a difficult differential diagnosis. Acta Otorhinolaryngol Ital 2005; 25(2):116-119. [https://www.ncbi.nlm. nih.gov/pubmed/16116835]

3. Kalfas S, Figdor D, Fracds, DE, Sundqvist G. A new bacterial species associated with failed endodontic treatment: Identification and description of Actinomyces radicidentis. Oral Surg. Oral Med. Oral Pathol. Oral Radiol. Endod. 2001; 92(2): 208-214. [https://www. ncbi.nlm.nih.gov/pubmed/11505269].

4. Jamshidi D, Moazami F, Sobhnamayan F, Taheri A. Clinical and Histopathologic Investigation of Periapical Actinomycosis with Cutaneous Lesion: a Case Report. Journal of Dentistry. 2005; 16(3): 286-290. [https://www.ncbi.nlm. nih.gov/pubmed/26535411]

5. Hirshberg A, Tsesis I, Metzger Z, Kaplan I. Periapical actinomycosis: a clinicopathologic study. Oral Surg. Oral Med. Oral Pathol. Oral Radial. Endod. 2003; 95: 614-620. [https:// 
www.ncbi.nlm.nih.gov/pubmed/12738954]

6. Sakellariou PL.Periapicalactinomiycosis:Report of a case and review of the literature. Endod Dent Traumatol 1996; 12:151-154. [https:// www.ncbi.nlm.nih.gov/pubmed/9028194]

7. Scotti K, Pousa MS, Orlando A. Actinomicosis periapical radicular: Reporte de un caso y revisión de la bibliografía. Acta Odontol Venez 2006; 44(3). [http://www.scielo. org.ve/scielo.php?script=sci_arttext\&pid =S0001-63652006000300016]

8. Pasupathy SP, Chakravarthy D, Chanmougananda S, Preeti PN. Periapical actinomycosis. BMJ Case Rep 2012. [cited 2012 Aug 1]. Available from: URL: <www. pubmedecentral.nih.gov>. [https://www.ncbi. nlm.nih.gov/pubmed/22854234]

9. Freeman LR, Zimmermann EE, Ferrillo PJ. Conservative treatment of periapical actinomycosis. Oral Surg 1981; 51:205-208. [https://www.sciencedirect.com/science/article/ pii/0030422081900402]

10. Oppenheimer S, Miller GS, Knopt K, Blechman H. Periapical Actinomycosis: An unusual case report. Oral Surg 1978; 36: 101. [https:// www.sciencedirect.com/science/article/ pii/0030422078904437]

11. Wesley, RK; Osborn, TP; Dylewski, JJ. Periapical actinomycosis: clinical considerations. Journal of Endodontics 1977; 9(3). [https://www.ncbi. nlm.nih.gov/pubmed/269899]

12. Ricucci D, Siqueira JF Jr. Apical actinomycosis as a continuum of intraradicular and extraradicular infection: case report and critical review on its involvement with treatment failure. J Endod. 2008; 34: 1124-1129. [https://www.ncbi.nlm.nih. gov/pubmed/18718379]

13. Farhad AR, Ajami M, Rastegar Khosravi M. Resolution of a Cutaneous Lesion Associated with a Periapical Actinomycosis Following Endodontic Surgery: A Case Report. Shiraz Univ Dent J 2012; 13(1): 40-43. [http:// dentjods.sums.ac.ir/index.php/JDSUMS/article/ download/63/61]

14. Mora M, Papadakis S, Guilarte C. Aspectos microbiológicos de la actinomicosis periapical: revisión de la literatura. Microbiological aspect of periapical actinomycosis. Acta Odontol Venez 2014; 52(3). [http://pesquisa.bvsalud. org/bvsecuador/resource/pt/lil-778006]

15. Esteves LS, Henriques ÁCG, Silva CÁVME, Cangussu MCT, Ramos EAG, Estrela C, et al. Actinomycosis is not Frequent in the Periapex But is a Persistent Lesion. Braz Dent J. 2017 Nov-Dec;28(6):688-693. 688]

Submetido em: 19-7-2018

Aceito em: 13-11-2018 